\title{
The Blended Instruction on Cloud via an Interactive Augmented Reality Technology Model to Enhance Digital Literacy
}

\author{
Thongkhane Soutthaboualy ${ }^{1}$, Pinanta Chatwattana ${ }^{1} \&$ Pallop Piriyasurawong ${ }^{1}$ \\ ${ }^{1}$ King Mongkut's University of Technology North Bangkok, Bangkok, Thailand \\ Correspondence: Thongkhane Soutthaboualy, King Mongkut's University of Technology North Bangkok, \\ Thailand. Tel: 66-966-731-235. E-mail: namotk@gmail.com
}

$\begin{array}{lcc}\text { Received: July 25, } 2021 & \text { Accepted: August 20, } 2021 \quad \text { Online Published: August 23, } 2021 \\ \text { doi:10.5539/hes.v11n3p144 } & \text { URL: https://doi.org/10.5539/hes.v11n3p144 }\end{array}$

\begin{abstract}
The objectives of the study were 1) Synthesize the conceptual framework of blended instruction on the cloud via an interactive augmented reality technology model to enhance digital literacy, 2) Design the blended instruction on the cloud via an interactive augmented reality technology model, 3) Develop the blended instruction on the cloud via an interactive augmented reality technology model, and 4) Study the suitability assessment of the blended instruction on the cloud via an interactive augmented reality technology model. The proposed model develops digital literacy skills, one of the most important skills for learners in the 21 st century that contributes to the learning society in the digital world. The samples group used in the study were nine experts in higher education. Then analyzing the data obtained from the assessment, using mathematic mean and standard deviation. Results of the assessment found the following. 1) The developed teaching and learning model consisted of four components: inputs, blended instruction on cloud processes, outcomes, and feedback. 2) The blended instruction on the cloud processes consists of 3 steps: the preparation, teaching and learning, presentation and summary of the learning results. 3) The assessment of the suitability of the developed teaching and learning model was at the highest appropriate. 4) The suitability assessment in the developed teaching and learning model was at the highest appropriate.
\end{abstract}

Keywords: blended instruction, cloud learning, interactive augmented reality, digital literacy

\section{Introduction}

The education development plan of the Lao People's Revolutionary Party and government of the Lao People's Democratic Republic, the 8th of the 5-year plan (2021-2025), has emphasized improving learning quality. Pay attention to teachers' teaching quality, equipment, curriculum, and laboratories to reduce teaching the theory but emphasizes more practicality (Ministry of Education and sports Lao PDR, 2021). Teaching innovation in digital universities (Chatwattana, 2021) is essential for teachers to pay attention and apply them in the current world situation to promote self-learning. It also raises the quality of social services, especially in education. Knowledge sharing and interactions through social networks resulted in Thai people having unlimited access to information. Teaching and learning and life-long learning processes must adapt based on innovation and digital technology.

Building a quality and efficient education system to be the primary mechanism for developing the potential and capability of a human can support education, learning, and challenges as the dynamics of the 21st century (Office of the Education Council, 2016). It focuses on students to seek knowledge by themselves, practical, focus on skills development, and building good attitude for life-long learning. Besides, the learners must participate in teaching and learning management plans, evaluate learning results, knowledge sharing, and interactions through social networks (Boonphak, 2020). Besides, having unlimited access to information based on innovation and digital technology.

Blended learning is a learning model that integrates face-to-face teaching and learning and online teaching and learning, emphasizing engaging learners. At the same time, the teacher acts as a facilitator to give advice and follow-up on learning outcomes both online and offline. Blended learning combining teaching and learning methods in the classroom, along with other processes using online tools. At the same time, it combines technological and communication strategies developed by distance learning through an interactive and vibrant learning environment (Martín-Martínez, Sainz \& Rodríguez-Legendre, 2020). The highlight of the blended learning model is the student-centre learning system, which requires students to participate in individual groups 
or personal learning activities actively. Assist students in gaining confidence, motivating themselves to present ideas, and respecting and appreciating their friends' opinions in the classroom (Hasanah \& Malik, 2020).

Presently, self-directed learning is a popular learning style, as information technology plays an essential role in learning young learners who emphasize active learning through media and information technology focused on enabling learners to experience self-learning. To develop students to be skilled and capable of planning their studies by self-learning. Besides, seek learning resources and self-assessment of learning. Also, teaching activities promote learning for students in another channel (Chatwattana \& Phadungthin, 2019).

Cloud Learning is an online computing technology in real-time. It is the application of processing technology on the Internet to accompany the teaching and learning process. Learners can learn on their own and learn from anywhere, at any time. There are tools to assist teachers in classroom management (Boonprasom \& Sintanakul, 2019). Cloud computing is the use of external data centres for processing, so it is an economic advantage. Cause universities do not pay for and maintain expensive hardware on-site anymore. Just use it through cloud providers such as Amazon, Google, or Microsoft; it means no longer needed that their computers (Pence, 2020).

Augmented reality technology is a technology that combines reality and the virtual world through devices and software. It can display three-dimensional images, graphics, and text to overlay with the real world through devices such as computers, smartphones, tablets or wearable devices (Bojukrapan, 2018). The application of augmented reality technology in learning and teaching should allow students to collaborate to assist them in understanding lessons and their interest in learning. Augmented reality technology can be applied to other technologies in education and provide information to students anywhere with a virtual reality experience. Then leads to collaboration between students and a deep understanding of what they are learning (Wittayakhom \& Piriyasurawong, 2020).

Digital literacy skills are skills for understanding and using digital technology that promotes lifelong learning to create a learning society using information technology. It is one of the 21 st-century skills that learners need to learn. The creation of new knowledge is at the core of all essential literacies. Likewise, digital literacy is also at the heart of generating further information digitally by adapting, applying, designing, inventing, or authoring information. Digital literacy is the ability to achieve information by using information technology, using software and digital technology, and cognition and generating information from digital tools (Pratolo \& Solikhati, 2021).

From the above theory, principles, and rationale, the researcher willing to develop the blended instruction on the cloud via an interactive augmented reality technology model to enhance digital literacy. So students can learn by themselves through teaching and learning that apply cloud technology to assist online teaching and learning. Besides, create interest in teaching and learning with interactive augmented reality technology of learners in digital access and use. It develops digital literacy skills, one of the most important skills for learners in the 21 st century that contributes to the learning society in the digital world.

\section{Research Objective and Hypothesis}

In this study, the researcher set the objectives as follows:

- Synthesize the conceptual framework of blended instruction on the cloud via an interactive augmented reality technology model to enhance digital literacy.

- Design the blended instruction on the cloud via an interactive augmented reality technology model to enhance digital literacy.

- Develop the blended instruction on the cloud via an interactive augmented reality technology model to enhance digital literacy.

- Study the development of the blended instruction on the cloud via an interactive augmented reality technology model to enhance digital literacy.

The research hypothesis is to study the assessment results of the suitability of the developed blended instruction model. The hypothesis in the study is as follows.

- Assessment of the suitability of the development of the blended instruction on the cloud via an interactive augmented reality technology model to enhance digital literacy is highly appropriate.

- Assessment of the suitability of the development of processes of the blended instruction on the cloud via an interactive augmented reality technology model to enhance digital literacy is highly appropriate. 


\section{Methodology}

The study develops blended instruction on the cloud via an interactive augmented reality technology model to enhance digital literacy. In addition, the researcher has applied the theory of blended learning, self-directed learning theory, cloud learning theory, and augmented reality technology as the basis for design and development. The researcher conducted the research under the research objectives by the concept idea of development is based on a systematic method and instructional design, adapted from ADDIE model by analyzing, design, development, and evaluation as follows: (1) Analyze and synthesize the conceptual framework of blended instruction on the cloud via an interactive augmented reality technology model to enhance digital literacy, (2) Design the blended instruction on the cloud via an interactive augmented reality technology model, (3) Develop the blended instruction on the cloud via an interactive augmented reality technology model, and (4) Study the assessment of the suitability of the blended instruction on the cloud via an interactive augmented reality technology model.

3.1 Synthesize the Conceptual Framework of Blended Instruction on the Cloud via an Interactive Augmented Reality Technology Model to Enhance Digital Literacy

Initially, the researcher studied theories, articles and related researches, including blended learning (Carman, 2002; Thaiposri \& Pririyasulawong, 2014; Nasongkhla, 2018; Wannapiroon, 2011), self-directed learning (Knowles, 1975; Wangkid, Onming \& Kasemnet, 2017; Promdaung, Wangsathittwong \& Tansriwong, 2018), cloud learning (Thanachawengsakul \& Jeerungsuwan, 2018; Boonprasom \& Sintanakul, 2019; Ruttanatiraku, 2018; Saenboonsong, 2017), augmented reality technology (Ditcharoen \& Ratthirom, 2016; Meesuwan, 2011), interactive media (Chaikhunpol, 2017; Phaladetch \& Khlaisang, 2020), digital literacy (Haruehansapong, 2019; Wongyai, 2019), learning achievement (Srisa-ard, 2011), and satisfaction (Maslow, 2013). Next, the relevant theories were analyzed and synthesized to formulate a conceptual framework for the blended instruction on the cloud via an interactive augmented reality technology model to enhance digital literacy.

\subsection{Design the Blended Instruction on the Cloud via an Interactive Augmented Reality Technology Model to Enhance Digital Literacy}

At this stage, the researcher design the structure and prototype elements of the blended instruction on the cloud via an interactive augmented reality technology model to enhance digital literacy by using the concept of systematic approach (Khemmani, 2010). Combined with cloud teaching and learning management through Google classroom and augmented reality technology. The design process consists of 5 steps, objective setting stage, study and analysis of documents and related research stage, context analysis stage, design and development stage, and assessment stage.

\subsection{Design the Blended Instruction on the Cloud via an Interactive Augmented Reality Technology Model to Enhance Digital Literacy}

In this stage, the researcher develops the blended instruction on the cloud via an interactive augmented reality technology model to enhance digital literacy. By applying the concept of blended learning theory and self-directed learning as a basis for developing teaching and learning model and blended learning processes to use as a guideline for teaching and learning further.

\subsection{Study the Development of the Blended Instruction on the Cloud via an Interactive Augmented Reality Technology Model to Enhance Digital Literacy}

This stage assesses the suitability of the blended instruction on the cloud via an interactive augmented reality technology model to enhance digital literacy besides the developed cloud blended teaching and learning process. Assessment by experts in the design and development of teaching and learning on the web, computer, besides information and communication technology for education. Use the data analysis criteria in Kanasutra (1995).

\section{Results}

The results of the design and development of a conceptual framework of the blended instruction on the cloud via an interactive augmented reality technology model to enhance digital literacy can summarize as follows:

4.1 The Synthesis of a Conceptual Framework of the Blended Instruction on the Cloud via an Interactive Augmented Reality Technology Model to Enhance Digital Literacy

The result of the study of theories, articles and related researches to assign a conceptual framework of the blended instruction on the cloud via an interactive augmented reality technology model to enhance digital literacy. The details of the result from analysis and synthesis consist of 4 parts, as shown in Figure 1. 


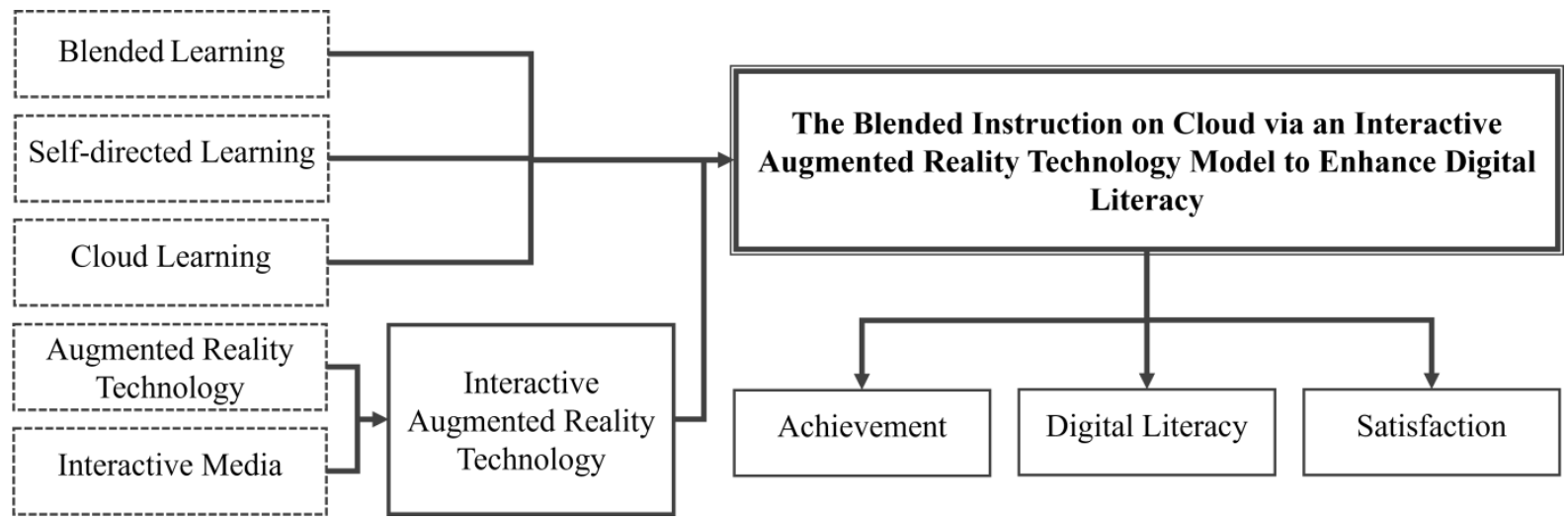

Figure 1. The conceptual framework of the blended instruction on the cloud via an interactive augmented reality technology model to enhance digital literacy

\subsection{The Development of the Blended Instruction on the Cloud via an Interactive Augmented Reality Technology Model to Enhance Digital Literacy}

The researcher developed the blended instruction on the cloud via an interactive augmented reality technology model follow the system approach process with apparent components. In addition, the researcher applies the concept of blended teaching and learning, cloud learning, and a self-directed learning process with augmented reality technology. As a guideline for developing the blended instruction on the cloud via an interactive augmented reality technology model. To get a model that is consistent with the purposed and meet users' needs, as shown in Figure 2.

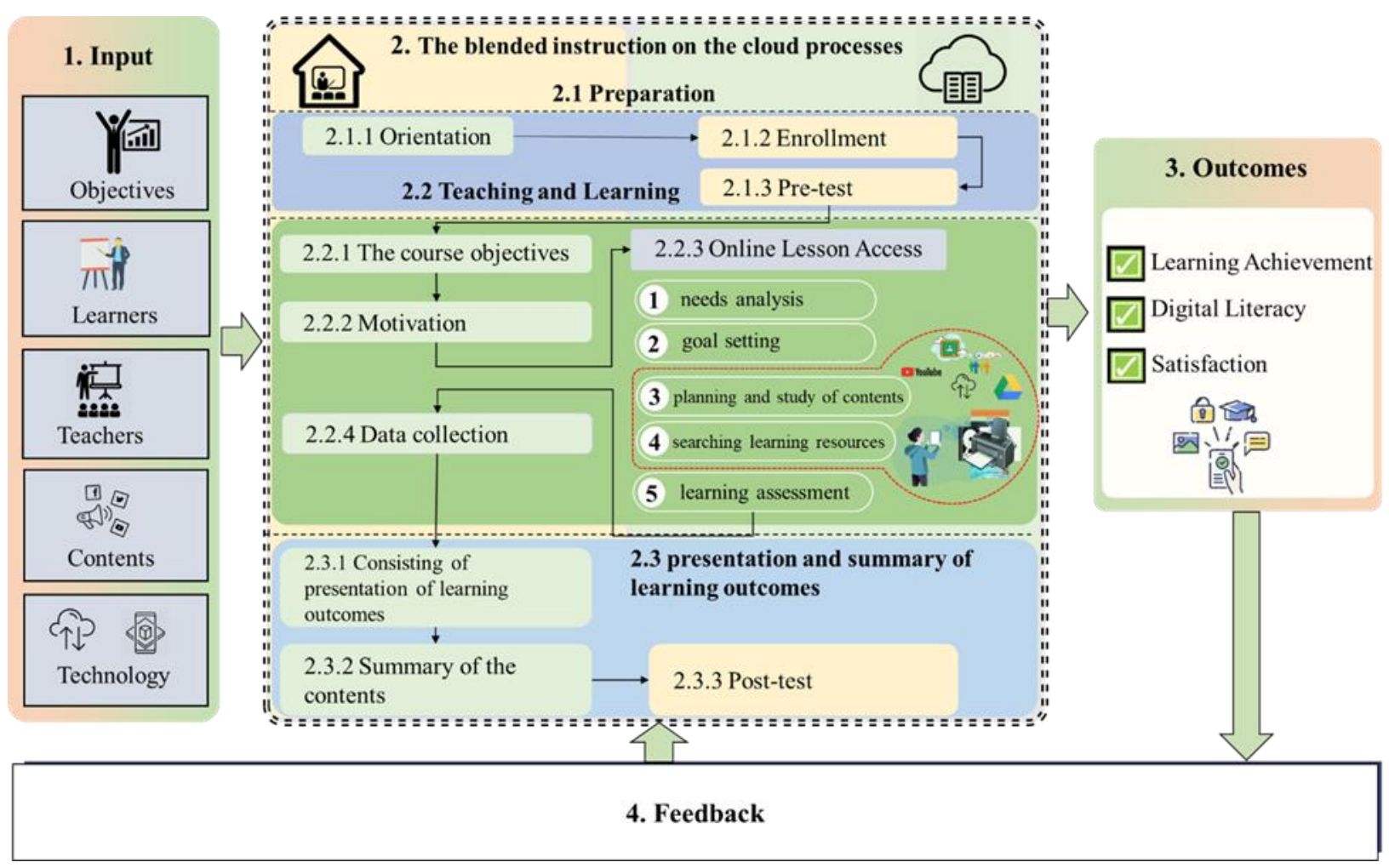

Figure 2. The blended instruction on the cloud via an interactive augmented reality technology model to enhance digital literacy

Figure 2 shows the blended instruction on the cloud via an interactive augmented reality technology model to enhance digital literacy, it consists of 4 main components as follows. (1) Inputs consisting of learning objectives, 
teachers, learners, contents, and technology. (2) The blended instruction on the cloud processes consist of 3 steps: preparation; teaching and learning, presentation and summary of learning results. (3) Outcomes consist of learning achievement, digital literacy, and satisfaction. (4) Feedback consists of experts' opinions, learning achievement, and digital literacy.

Table 1. Synthesis of desired characteristics from digital literacy skills (Haruehansapong, 2019; Wongyai, 2019)

\begin{tabular}{ll}
\hline Digital literacy & Desired characteristics \\
\hline Accessibility & $\begin{array}{l}\text { the result of learning when learners can access learning resources by using online } \\
\text { learning materials, to access information and communication technology for education } \\
\text { the result of learning when learners can apply information technology, } \\
\text { understand the job, able analyze and build a body of knowledge from digital media }\end{array}$ \\
\hline
\end{tabular}

\subsection{Results of the Development of Processes of the Blended Instruction on the Cloud via an Interactive Augmented Reality Technology Model to Enhance Digital Literacy}

The processes of blended instruction on the cloud via an interactive augmented reality technology model to enhance digital literacy, the researcher defines the steps of learning processes for blended instruction on the cloud by synthesizing from the self-directed learning process (Knowles, 1975) shown in Figure 3.

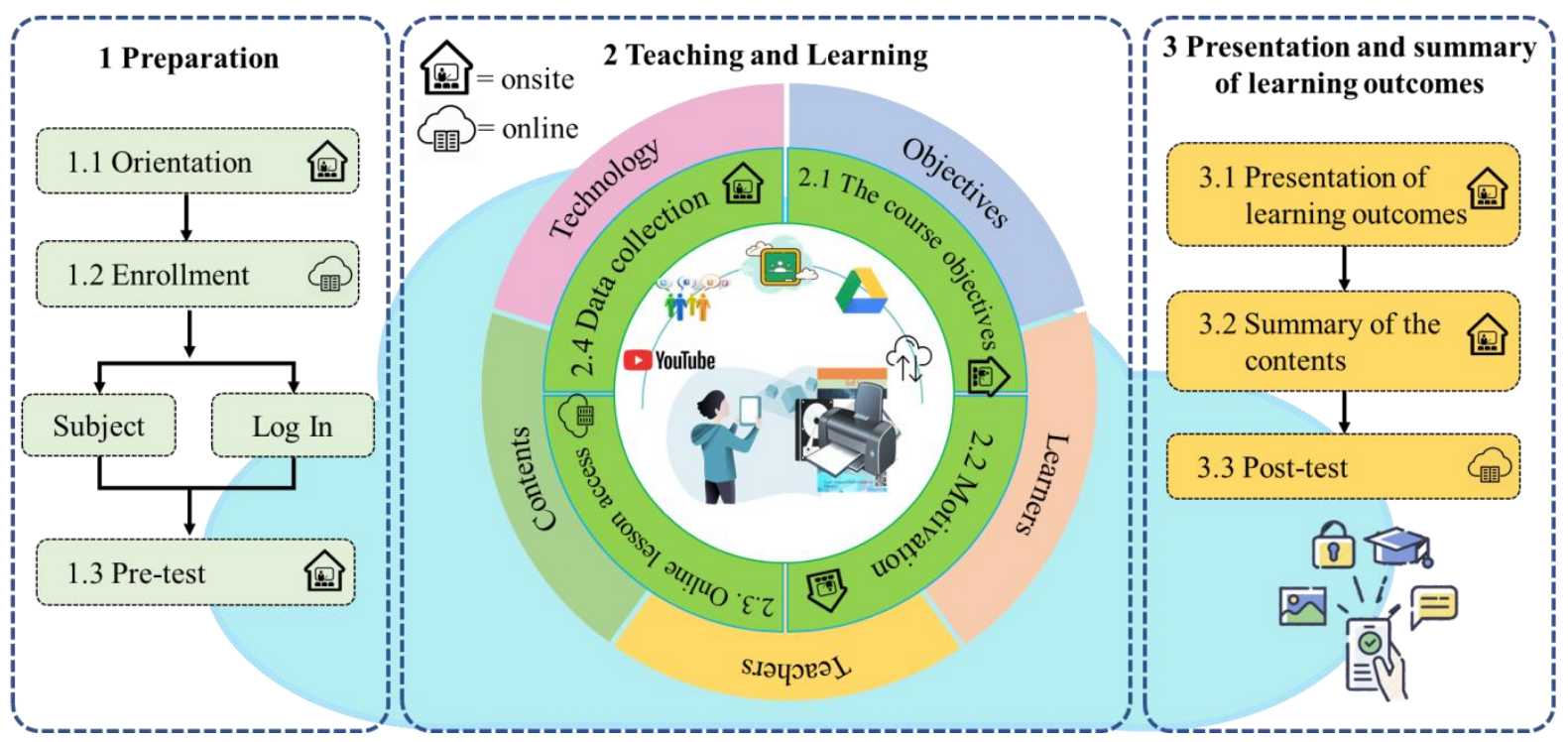

Figure 3. The processes of blended instruction on the cloud via interactive augmented reality technology model to enhance digital literacy

Figure 3 shows the processes of blended instruction on the cloud via an interactive augmented reality technology model to enhance digital literacy. It is one component of the blended instruction on the cloud via interactive augmented reality technology model to enhance digital literacy. It was synthesized from the self-directed learning process, and it was summarized in 4 steps as follows. (1) The preparation, consisting of orientation, enrollment, and pre-test. (2) Teaching and learning, including define the course objectives, motivation, online lesson access, and data collection. Online lesson access is when the learners enter the self-directed learning process consisting of 5 steps, including needs analysis, goal setting, planning and study of contents, searching learning resources, and learning assessment. While planning and studying the contents and searching learning resources, the learners are learning via cloud technology and interactive technology built by teachers on Google Classroom. The teachers provide a study guide, contents, worksheets, activities, quizzes, and AR code for learners to scan for access to augmented reality technology lessons. In the teaching step, the researcher analyzed the context to determine the components of teaching and learning to support the self-directed cloud learning via interactive augmented reality technology, including the course objectives, teachers, learners, contents, teaching and learning technology. (3) Presentation and summary of learning outcomes, consisting of presentation of learning outcomes, a summary of the contents, and post-test. 


\subsection{Results of Development of the Blended Instruction on the Cloud via an Interactive Augmented Reality Technology Model to Enhance Digital Literacy}

From the development of the blended instruction on the cloud via an interactive augmented reality technology model to enhance digital literacy, the results can be summarized into two parts. (1) The assessment results of the suitability of the development of the blended instruction on the cloud via an interactive augmented reality technology model to enhance digital literacy. (2) The assessment results of the suitability of processes of blended instruction on the cloud via an interactive augmented reality technology to enhance digital literacy. The details are as follows.

Table 2. The assessment results of the suitability of the development of the blended instruction on the cloud via an interactive augmented reality technology model to enhance digital literacy (Integrated components issue)

\begin{tabular}{llll}
\hline Assessment issues & \multicolumn{3}{l}{ Level of appropriateness } \\
\cline { 2 - 5 } & Mean & S.D. & Interpretation \\
\hline 1. Principles, concepts and theories use as the basis for design. & 4.56 & 0.73 & Highest \\
2. The purposes of the blended instruction on the cloud & 4.67 & 0.71 & Highest \\
via an interactive augmented reality technology model. & & & \\
3. The components of the blended instruction model. & & & \\
$\quad$ 3.1 Inputs & 4.67 & 0.50 & Highest \\
$\quad$ 3.2 Teaching and learning processes & 4.78 & 0.44 & Highest \\
3.3 Outcomes & 4.44 & 0.53 & High \\
3.4 Feedback & 4.67 & 0.71 & Highest \\
4. The suitability of sequence in the teaching and learning & 4.56 & 0.53 & Highest \\
processes of the blended instruction model. & & & \\
5. The integration of all components in the design of the & 4.44 & 0.73 & High \\
blended instruction model. & & & \\
Average & 4.60 & 0.61 & Highest \\
\hline
\end{tabular}

Table 2. The assessment results of the suitability of the development of the blended instruction on the cloud via an interactive augmented reality technology model to enhance digital literacy (Integrated components issue) had overall suitability at the highest appropriated (Mean $=4.60, \mathrm{SD}=0.61$ ). When considering each aspect of teaching and learning processes at the highest appropriate (Mean $=4.78$, S.D. $=0.44$ ). The teaching and learning process is an essential factor in the indispensable component of the blended instruction on the cloud via an interactive augmented reality technology model. Follow by the purposes of the blended instruction on the cloud via an interactive augmented reality technology model had suitability at the highest appropriated (Mean=4.67, $\mathrm{SD}=0.71$ ). It shows that the components as the teaching and learning model's objectives are apparent in their development. According to the assessment results, it may conclude that the developed blended learning model has overall components thoroughly so can use in teaching and learning to enhance digital literacy. 
Table 3. The assessment results of the suitability of the development of the blended instruction on the cloud via an interactive augmented reality technology model to enhance digital literacy (Individual component issue)

\begin{tabular}{llll}
\hline Assessment issues & \multicolumn{3}{l}{ Level of appropriateness } \\
\cline { 2 - 4 } & Mean & S.D. & Interpretation \\
\hline 1. Inputs & & & \\
1.1 Learning objectives & 4.78 & 0.44 & Highest \\
1.2 Teachers & 4.67 & 0.50 & Highest \\
1.3 Learners & 4.33 & 0.71 & High \\
1.4 Contents & 4.56 & 0.53 & Highest \\
1.5 Technology & 4.67 & 0.50 & Highest \\
Average Input & 4.60 & 0.54 & Highest \\
2. Teaching and learning processes & & & \\
2.1 Preparation & 4.56 & 0.65 & Highest \\
2.2 Teaching and learning & 4.57 & 0.63 & Highest \\
2.3 Presentation and summary of learning results & 4.67 & 0.52 & Highest \\
Average Teaching and learning processes & 4.60 & 0.60 & Highest \\
3. Outcomes & & & \\
3.1 Learning achievement & 4.44 & 0.73 & High \\
3.2 Digital literacy & 4.67 & 0.50 & Highest \\
3.3 Satisfaction & 4.67 & 0.50 & Highest \\
Average Outcomes & 4.59 & 0.58 & Highest \\
4. Feedback & & & \\
4.1 Learning achievement & 4.67 & 0.50 & Highest \\
4.2 Digital literacy & 4.56 & 0.73 & Highest \\
4.3 Experts' opinions & 4.78 & 0.44 & Highest \\
Average Feedback & 4.67 & 0.56 & Highest \\
Overall Average & 4.60 & 0.59 & Highest \\
\hline
\end{tabular}

Table 3. It found that the assessment results of the suitability of the development of the blended instruction on the cloud via an interactive augmented reality technology model to enhance digital literacy (Individual component issue) had overall suitability at the highest appropriated (Mean=4.60, S.D. $=0.59$ ). When considering each aspect, 1) Inputs at the highest appropriated (Mean=4.60, S.D.=0.54). The learning objectives at the highest appropriated (Mean=4.78, S.D.=0.44), due to the study had apparent learning objectives. In contrast, the learners at highly appropriated (Mean= 4.33, S.D. $=0.71$ ), because the proposed model lacks a clear explanation of the qualifications of the learners. 2) Teaching and learning processes at the highest appropriate (Mean= 4.60, S.D. $=0.60$ ). Whereas presentation and summary of learning results at the highest appropriated (Mean $=4.67$, S.D.=0.52). Due to it has the process to finalizing the knowledge of learners appropriately. At the same time preparation at the highest appropriate (Mean $=4.56$, S.D. $=0.65$ ), cause the preparation process before entering the lesson is appropriate to motivate the learners. 3) Outcomes at the highest appropriate (Mean= 4.59, S.D.=0.58). Digital literacy at the highest appropriate (Mean= 4.67, S.D. $=0.50)$. In contrast, learning achievement at highly appropriated (Mean=4.44, S.D.=0.73), due to the learning assessment process still lack an apparent explanation in some aspects. 4) Feedback at the highest appropriate (Mean= 4.67, S.D.=0.56). Experts' opinions at the highest appropriate (Mean= 4.60, S.D.=0.59), because use recommendations and feedback of the experts to improve the teaching and learning model. Results in a developed blended instruction model completed and relevant to the learners' needs. At the same time, digital literacy had the highest appropriate (Mean $=4.56$, S.D. $=0.73$ ), it shows that digital literacy of the students' is essential as a result of teaching and learning. The assessment results may conclude that the developed blended instruction model has components suitable for practical use, leading to the overall assessment at the highest appropriate. In addition, it can use as a guideline to the blended learning of learning in a classroom and self-directed learning as a tool to enhance students' self-learning. 
Table 4. The assessment results of the suitability of processes of development of blended instruction on the cloud via an interactive augmented reality technology to enhance digital literacy

\begin{tabular}{llll}
\hline Assessment issues & \multicolumn{3}{l}{ Level of appropriateness } \\
\cline { 2 - 4 } & Mean & S.D. & Interpretation \\
\hline 1. Preparation & & & \\
1.1 Orientation & 4.67 & 0.50 & Highest \\
1.2 Enrollment & 4.44 & 0.73 & High \\
1.3 Pre-test & 4.56 & 0.73 & Highest \\
Average Preparation & 4.56 & 0.65 & Highest \\
2. Teaching and learning & & & \\
2.1 Define course objectives & 4.67 & 0.71 & Highest \\
2.2 Motivation & 4.67 & 0.50 & Highest \\
2.3 Online lesson access with self-directed learning & & & \\
$\quad$ 1) Needs analysis & 4.44 & 0.73 & High \\
$\quad$ 2) Goals setting & 4.44 & 0.73 & High \\
$\quad$ 3) Planning and studying of the contents & 4.67 & 0.50 & Highest \\
$\quad$ 4) Searching learning resources & 4.78 & 0.44 & Highest \\
$\quad$ 5) Learning assessment & 4.44 & 0.73 & High \\
2.4 Data collection & 4.44 & 0.73 & High \\
Average Teaching and learning & 4.54 & 0.64 & Highest \\
3. Presentation and summary of the study results & & & \\
3.1 Presentation of the study results & 4.67 & 0.50 & Highest \\
3.2 Summary of the study results & 4.44 & 0.73 & High \\
$\quad$ 3.3 Post-test & 4.89 & 0.33 & Highest \\
Average Presentation and summary of the study results & 4.67 & 0.52 & Highest \\
Overall Average & 4.60 & 0.59 & Highest \\
\hline
\end{tabular}

Table 4. It found that the assessment results of the suitability of processes of development of the blended instruction on the cloud via an interactive augmented reality technology to enhance digital literacy had overall suitability at the highest appropriated (Mean=4.60, $\mathrm{SD}=0.59$ ). When considering each aspect, 1) Preparation at the highest appropriate (Mean= 4.56, S.D. $=0.65$ ). Orientation at the highest appropriate (Mean=4.67, S.D. $=0.50$ ), due to it is an essential process to understand before learning. Whereas enrollment at the highest appropriate (Mean= 4.44, S.D.=0.73), because enrollment is a process that needs to register through an online system. 2) Teaching and learning at the highest appropriate (Mean= 4.54, S.D. $=0.64)$. Motivation at the highest appropriate (Mean= 4.67, S.D. $=0.50$ ), indicated that motivating students before class is an essential process for students to learn. Whereas data collection at the high appropriate (Mean= 4.44, S.D. $=0.63$ ), due to the data collection process is takes time to synthesize knowledge from the lessons developed. 3) Presentation and summary of the study results at the highest appropriate (Mean= 4.67, S.D. $=0.52$ ). Post-test at the highest appropriated (Mean= 4.89, S.D. $=0.33$ ), indicated that learning assessment is an essential process after teaching and learning. In addition, summary of the learning results at highly appropriated (Mean=4.44, S.D. $=0.73$ ), because the summary of the results is done in the classroom, which can deploy online as appropriate. The study results may conclude that the developed blended instruction on the cloud via an interactive augmented reality technology model to enhance digital literacy has appropriate components, procedures, and processes. It can be used as a guideline to develop blended instruction on the cloud via an interactive augmented reality technology model to enhance students access to learning resources on self-directed learning to achieve higher digital literacy and learning achievement. 
Table 5. The assessment results of the suitability of development of the blended instruction on the cloud via an interactive augmented reality technology to enhance digital literacy

\begin{tabular}{llll}
\hline Assessment issues & \multicolumn{3}{l}{ Level of appropriateness } \\
\cline { 2 - 4 } & Mean & S.D. & Interpretation \\
\hline $\begin{array}{l}\text { 1. The blended instruction on the cloud via an interactive augmented reality } \\
\text { technology model is suitable for enhancing higher learning achievement. }\end{array}$ & 4.67 & 0.52 & Highest \\
$\begin{array}{l}\text { 2. The blended instruction on the cloud via an interactive augmented reality } \\
\text { technology model is suitable for enhancing digital literacy. }\end{array}$ & 4.89 & 0.35 & Highest \\
$\begin{array}{l}\text { 3. The blended instruction on the cloud via an interactive augmented reality } \\
\text { technology model is suitable to enhance digital literacy as a practical possibility. }\end{array}$ & 4.67 & 0.46 & Highest \\
Average & 4.74 & 0.44 & Highest \\
\hline
\end{tabular}

Table 5. It found that the assessment results of the suitability of development of the blended instruction on the cloud via an interactive augmented reality technology to enhance digital literacy had overall suitability at the highest appropriated (Mean=4.74, S.D.=0.44). The blended instruction on the cloud via an interactive augmented reality technology to enhance digital literacy when considering each aspect, it is suitable to enhance digital literacy at the highest appropriated (Mean=4.89, S.D.=0.35). Follow by the blended instruction on the cloud via an interactive augmented reality technology model is suitable to enhance digital literacy as a practical possibility at the highest appropriated (Mean=4.67, S.D.=0.46), respectively. Conclude that the developed blended instruction model has suitability components, procedures, and teaching and learning processes. It can be used as a guideline to establish blended instruction on the cloud via an interactive augmented reality technology model to enhance students access to learning resources on self-directed learning to achieve higher digital literacy and learning achievement.

\section{Conclusion \& Discussion}

The blended instruction on the cloud via an interactive augmented reality technology to enhance digital literacy is an instruction model to support teaching-learning in the digital era to encourage learners with self-directed learning. It consists of 4 main components as follows: (1) Inputs are consisting of learning objectives, teachers, learners, contents, and technology, (2) Processes of the blended instruction on the cloud consisting of 3 steps: preparation; teaching, presentation and summary of learning results, (3) Outcomes including learning achievement, digital literacy, and satisfaction, and (4) Feedback consists of experts' opinions, learning achievement, and digital literacy.

Processes of the blended instruction on the cloud via an interactive augmented reality technology to enhance digital literacy is one of the components of the blended instruction on the cloud via an interactive augmented reality technology developed by synthesized from self-directed learning processes, summarized in 3 steps: (1) Preparation, consisting of orientation, enrollment, and pre-test, (2) Instructional consist of define the course objectives, motivation, online lesson access, and data collection, and (3) Presentation and summary of results, consisting of presentation of results, a summary of contents, and post-test.

The results of the study can be summarized as the following. (1) The results of the development of the blended instruction on the cloud via an interactive augmented reality technology model to enhance digital literacy (Integrated components) had the overall suitability at the highest appropriate (Mean=4.60, SD=0.61). (2) The results of the development of the blended instruction on the cloud via an interactive augmented reality technology model to enhance digital literacy (Individual component) had the overall suitability at the highest appropriate (Mean=4.60, S.D.=0.59). (3) The assessment of developing processes of the blended instruction on the cloud had the overall suitability at the highest appropriate (Mean=4.60, SD=0.59). (4) The assessment of the blended instruction on the cloud via an interactive augmented reality technology model to enhance digital literacy had the suitability at the highest appropriate (Mean=4.74, S.D.=0.44). The summary of the above findings is consistent with the study of Martín-Martínez, Sainz \& Rodríguez-Legendre (2020) study "Evaluation of a blended learning model for pre-service teachers". It found that the combined teaching arrangement consists of five components as follows (web2.0, social relations, cooperative learning, expectations and feedback). The application of the blended instruction model as an additional element in teaching assist in enhancing the development of knowledge and skills both individually and in collaboration or group work. It is also consistent with Piromnok (2019) study "An Instructional Model Development in Computer Graphic Course Focusing on Self-directed Learning Process of Information Technology Undergraduate Student, Suan Dusit University", which found that when changed the instructional model from the traditional demonstration method, learners 
follow, switching to the learners set their own goals, by what they want to do, and define the scope of their work. In comparison, a teacher is the one who outlines the framework for the students. Then let the learners searching for knowledge related to what they want to do. Next, the learners make their selection and act on what they have chosen. By the way, this method assists students to become more enthusiastic in learning. Because students are the ones who set goals and decide to do what they want to do, lastly, help learners focus more than their teachers setting goals, topics, and methods. Also, it is consistent with the study of Wittayakhom \& Piriyasurawong (2020) study "Learning Management STEAM Model on Massive Open Online Courses Using Augmented Reality to Enhance Creativity and Innovation". The research conducted with seven experts, the study found that the developed learning model has the suitability at the highest appropriate. The learning process by using augmented reality technology in conjunction with an open online learning process can encourage learners to creativity and innovation successfully. It is consistent with the study of Jantakoon, Wannapiroon \& Nilsook (2019) "Virtual Immersive Learning Environments (VILEs) Based on Digital Storytelling to Enhance Deeper Learning for Undergraduate Students", stated that augmented reality in teaching and learning could motivate students to be more interested in teaching and learning. Learners can collaboratively work and enhance their learning outcomes.

\section{Recommendations for the Study}

1. The study of the blended instruction on the cloud via an interactive augmented reality technology to enhance digital literacy. It revealed that the developed model has completed components with a practical learning process and assist learners to enhance their digital literacy. The proposed model has assessment and revised by experts in teaching and information technology. For further study, the researchers will use the model to implement with samples to complete the research.

2. For those interested in applying the proposed model to practical use, there may be some factors to concern, such as the ability of an instructor to create the media, accessibility to technology, and media usage by learners. Also, cloud technology and augmented reality may face obstacles to data communication transmission rate, stability, reliability, and coverage area of the network. Besides, cost to consumed of technology.

\section{References}

Bojukrapan, S. (2018). Development of Multimedia's English Vocabulary with Augmented Reality Technology. Journal of Technology Management Rajabhat Maha Sarakham University, 3(2), 58-64.

Boonphak, K. (2020). Learning Management Era New Normal. Journal of Industrial Education, 19(2), A1-A6.

Boonprasom, C., \& Sintanakul, K. (2019). The Synthesis of Model of Collaborative to Enhance Critical Thinking of Undergraduate Student. Journal of Industrial Education, 18(3). 165-173.

Chatwattana, P. (2021). A MOOC System with Self-directed Learning in a Digital University. Global Journal of Engineering Education, 23(2), 134-142.

Chatwattana, P., \& Phadungthin, R. (2019). Web-based Virtual Laboratory for the Promotion of Self-directed Learning. Global Journal of Engineering Education, 21(2), 157-164.

Carman, J. M. (2002). Blended Learning Design: Five Key Ingredients. Retrieved from http://blended2010.pbworks.com/f/Carman.pdf

Chaikhunpol, N. (2017). The Communication Interaction of Thai When Using Social Networking Media. Payup University Journal, 27(2), 55-65.

Ditcharoen, N., \& Ratthirom, A. (2016). Development of 3D Zoo Book using Augmented Reality Technology on Android. Journal of Research Unit on Science, Technology and Environment for Learning, 7(1), 77-87.

Haruehansapong, K. (2019). Digital Literacy of Undergraduate Students at Walailak University. Walailak Journal of Learning Innovations, 5(2), 24-40.

Jantakoon, T., Wannapiroon, P., \& Nilsook, P. (2019). Virtual Immersive Learning Environments (VILEs) Based on Digital Storytelling to Enhance Deeper Learning for Undergraduate Students, Higher Education Studies, 9(1), 144-150. https://doi.org/10.5539/hes.v9n1p144

Kanasutra, P. (1995). Statistics for Research in the Behavioral Sciences. Bangkok: Chulalongkorn University Press

Khemmani, T. (2010). Science of Teaching: Knowledge of Efficient Learning Process Management. Bangkok: Chulalongkorn University Press.

Knowles, M. S. (1975). Self-directed Learning: A Guide for Learners and Teachers. New York: Association 
Press.

Meesuwan, W. (2011). Augmented Reality Technology for Learning. Journal of Education Naresuan University, 13(2), 119-128.

Maslow, A. (2013). A Theory of Human Motivation. Mansfield Centre: Martino Publishing.

Ministry of Education and Sports Lao PDR. (2020). Education and sport develop Plan (2021-2025). Ministry of Education and sports, Lao PDR.

Martín-Martínez, L., Sainz, V., \& Rodríguez-Legendre, F. (2020). Evaluation of a blended learning model for pre-service teachers. Knowledge Management \& E-Learning, 12(2), 147-164. https://doi.org/10.34105/j.kmel.2020.12.008

Hasanah, H., \& Malik, M. N. (2020). Blended learning in improving students' critical thinking and communication skills at University. Cypriot Journal of Educational Sciences, 15(5), 1295-1306. https://doi.org/10.18844/cjes.v15i5.5168

Pence E. H. (2020). How Should Chemistry Educators Respond to the Next Generation of Technology Change? Education Sciences, 10(2), 34. https://doi.org/10.3390/educsci10020034

Piromnok, N. (2019). An Instructional Model Development in Computer Graphic Course Focusing on Self-directed Learning Process of Information Technology Undergraduate Student, Suan Dusit University. Vocational Education Innovation and Research Journal: VE-IRJ, 3(1), 51-57.

Nasongkhla, J. (2018). Digital Learning Design. Bangkok: Chulalongkorn University Press.

Office of the Education Council. (2016). National Education Plan Framework (B.E. 2560-2574). Bangkok: Office of the Education Council Ministry of Education.

Promdaung. W., Wangsathittwong. M., \& Tansriwong, S. (2018). Development of an Instructional Model of a Self Directed Learning Laboratory for Undergraduate Students. The Golden Teak: Humanity and Social Science Journal, 24(1), 142-155.

Phaladetch, D., \& Khlaisang, K. (2020). Development of Interactive Learning Environment Using Discussion Method with Think-Talk-Write Technique Model to Enhance Mathematical Communication Ability of Upper Secondary Students. Journal of Information and Learning, 31(2), 45-57.

Pratolo, W. B., \& Solikhati. A. H. (2021). Investigating teachers' attitude toward digital literacy in EFL classroom. Journal of Education and Learning (EduLearn), 15(1), 97-103. https://doi.org/10.11591/edulearn.v 15 i1.15747

Ruttanatiraku, A. (2018). Education as a Service for Instructional in the Digital Age. Journal of Pacific Institute of Management Science, 4(1), 308-320.

Saenboonsong, S. (2017). The Development of Flipped Classroom Model using Cloud Technology Approach on Academic Achievement in Computer Science for Teacher Course for Undergraduate Students. Journal of Graduate Studies Valaya Alongkron Rajabhat University, 11(Special), 133-146.

Srisa-ard, B. (2011). Beginning of Research. Bangkok: Suweerivasarn Company Limited.

Thanachawengsakul, N., \& Jeerungsuwan, N. (2018). Instructional Model of MIAP on Cloud Computing Technology of Under Graduation Student in Order to Promote 21st Century Learning Skill. Journal of Education Naresuan University, 20(4), 58-69.

Thaiposri, P., \& Pririyasulawong, P. (2014). Blended Learning using Augmented Reality. Journal of Education Naresuan University, 16(3), 214-222.

Wangkid, M., Onming. R., \& Kasemnet, L. (2017). Develop of Instructional Model for Information Technology focused on Self-directed Learning in Flipped Learning with Grade Seven Student. Phranakhon Rajabhat Research Journal Humanities \& Social Sciences, 12(1), 190-204.

Wannapiroon, P. (2011). Blended Learning: Principles into Practice. Journal of Vocational and Technical Education, 1(2), 43-49.

Wongyai, N. (2019). A Guide to Developing Digital Literacy Skills of Digital Native. Veridian E-Journal, Silpakorn University (Humanities, Social Sciences and Arts), 10(2), 1631-1642.

Wittayakhom, N., \& Piriyasurawong, P. (2020). Learning Management STEAM Model on Massive Open Online Courses Using Augmented Reality to Enhance Creativity and Innovation. Higher Education Studies, 10(4), 
44-53. https://doi.org/10.5539/hes.v10n4p44

\section{Copyrights}

Copyright for this article is retained by the author(s), with first publication rights granted to the journal.

This is an open-access article distributed under the terms and conditions of the Creative Commons Attribution license (http://creativecommons.org/licenses/by/4.0/). 